\title{
Do Job Seekers Benefit from Contacts? A Direct Test with Contemporaneous Searches
}

\author{
Elena Obukhova, George Lan MIT Sloan School of Management, Massachusetts Institute
} of Technology, Cambridge, Massachusetts 02142 \{obukhova@mit.edu, gjlan@mit.edu\}

\begin{abstract}
Although it is intuitively plausible that a job seeker benefits by using contacts in her job search, the literature is plagued by theoretical disagreements and inconclusive empirical evidence. Single-firm studies consistently find that job seekers applying through referrals achieve better labor-market outcomes than job seekers applying without referrals, but the evidence from jobseeker studies is mixed. To solve this puzzle, we clarify the distinction between having social capital and using contacts as a search method. We present theoretical reasons to suggest that the lack of an association between a job seeker's social capital and whether or not she uses social networks to search for a job should not be taken to imply that job seekers who use social networks to search for jobs do not benefit from using contacts. We exploit a strategic research setting, the school-to-work transition of 291 university graduates who engaged in 3,112 contemporaneous job searches, to show that although a job seeker's social capital may not affect whether or not she uses contacts to search for a job, using contacts as a job-search method does improve her job-search outcomes. We conclude by discussing the implications of our findings for the literature on job search and social networks.
\end{abstract}

\section{Introduction}

"It's not what you know, but who you know." This is not only a nugget of popular wisdom and practical experience, but a concise summary of much of the sociological theorizing on labor markets. It is intuitively plausible that a job seeker can improve her labor-market outcomes by using her contacts. For example, a contact might inform a job seeker about an opportunity that she would not have found through formal methods or that is a better match for her skills. Contacts may also provide information about a particular firm's hiring process, enabling the job seeker to apply at the right time or to submit a more appropriate application. The job seeker may also benefit from applying through contacts because employers prefer to hire referred candidates, assuming such candidates to have a better understanding of the job's requirements or to be more likely to fit in with the corporate culture.

Despite the plausibility of the claim that job seekers benefit from contacts, the literature is plagued by theoretical disagreement and inconclusive empirical evidence (for reviews, see Granovetter 1995; Marsden and Gorman 2001; Mouw 2003, 2006). The strongest evidence in favor of a causal effect of contacts on job-search outcomes comes from studies examining hiring processes at particular firms (Fernandez and Weinberg 1997, Fernandez et al. 2000, Petersen et al. 2000, Yakubovich and Lup 2006). These studies, which compare the outcomes for job seekers applying through referrals to those for job seekers applying without referrals, consistently find that the former group achieves better labor-market outcomes. Single- firm studies have been replicated in a variety of organizations, increasing our confidence in the generalizability of their results. 
In contrast, studies of individual job seekers have produced mixed results (for reviews, see Granovetter 1995, Marsden and Gorman 2001) and suffer from a variety of methodological shortcomings (see Montgomery 1992; Granovetter 1995; Fernandez and Weinberg 1997; Mouw 2003, 2006). Numerous studies find that job seekers with more social capital achieve better labor-market outcomes (de Graaf and Flap 1988, Lai et al. 1998, Völker and Flap 2001, Lin 2002). However, this could be due to homophily in friendship networks; that is, the propensity to make friends similar to oneself (Mouw $2003,2006)$. The fact that individuals with more social capital are no more likely to use it to search for jobs than those with less social capital (Lai et al. 1998; Mouw 2002, 2003) appears to lend additional credibility to the notion that job seekers might not benefit from contacts.

To solve this important puzzle, we clarify the distinction between having social capital and using contacts as a job-search method. We present theoretical reasons to suggest that the lack of an association between a job seeker's social capital and whether or not she uses social networks to search for a job should not be taken to imply that job seekers who do use their social networks to search for jobs do not benefit from it. We exploit a strategic research site - job searches by recent university graduates - to show that although a job seeker's social capital has no effect on whether or not she uses contacts to search for a job, using contacts as a job-search method improves her labor-market outcomes. In short, having social capital might not have a causal effect on labor-market outcomes, but using it does.

We begin this paper by explaining two approaches that scholars have adopted to establish that social networks have a causal effect on labor-market outcomes: an indirect test that involves examining the association between having social capital and finding a job through social networks and a direct test that involves comparing, for the same individual, the outcomes of searching through different methods. Using our data, we show that even though the indirect test indicates that contacts do not matter, our improved direct testusing data on contemporaneous job-search histories - indicates that job seekers do benefit from using contacts. We conclude by outlining the implications of our study for the literature on job search and social networks.

\section{Theory}

Much of what we know about how social capital influences labor-market outcomes comes from social capital studies, or studies that focus on the relationship between a job seeker's social capital and her labor-market outcomes, such as wages or job satisfaction (see Figure 1). These studies consistently find that job seekers with more social capital achieve better labor-market outcomes than those with less social capital (e.g., de Graaf and Flap 1988, Boxman et al. 1991, Völker and Flap 2001). Yet these studies, despite their intuitive appeal, suffer from an important methodological problem: The relationship between a job seeker's social capital and her labor-market outcomes might be due to 
homophily in her friendship networks (Mouw 2003, 2006). For example, highly ambitious people are more likely to be friends with other highly ambitious people. They are also more likely to achieve better labor-market outcomes, independent of their friends' help. The possibility of an omitted variable on which the job seeker and her contacts are similar, such as ambition or some other personality trait, suggests that the relationship might be spurious rather than causal.

One way to examine whether social networks have a causal effect on labor-market outcomes has been an indirect test (Mouw 2003). Specifically, according to the rationalchoice multimethod job-search model (e.g., Holzer 1987), job seekers who expect higher returns from using a particular job-search method should be more likely to use that method than those who expect lower returns. Following this logic, if they expect to gain by doing so, job seekers with more social capital should be more likely to use contacts than otherwise identical job seekers with less social capital. Yet a growing number of studies find no association between having social capital and finding a job through social networks (e.g., Lai et al. 1998, Mouw 2003). 'Thus, based on the results of the indirect test, we cannot rule out the possibility that the association between a job seeker's social capital and her labor-market outcomes is spurious.

However, underlying the indirect test are some potentially problematic assumptions about a job seeker's inclination and ability to ask for and/or receive help from her contacts. First, several individual-level factors can account for an individual's inclination to mobilize her networks (for a review, see Burt 2011). For example, Smith et al. (2012) show that an individual's perception of her status shapes the network that she activatesthat is, calls to mind - when faced with a job threat. They argue that higher-status people, because they have more power, are more likely to act optimistically. In contrast, because low-status people have less power, the threat of joblessness might lead to self-doubt. Confirming these predictions, the authors find that higher-status individuals activate larger subsections of their networks than do low-status individuals. Studies such as these suggest that we might expect considerable variation among individuals in their propensity to use contacts for job search.

Second, using contacts is a two-way street, and we are only beginning to understand the sources of the variation in a contacts' behavior (e.g., Smith 2005, Marin 2012). For example, Smith (2005) finds that, among African American poor, some potential helpers are unwilling to help a job seeker because they fear that recommending an unreliable worker would damage their own reputations. Among white-collar workers, such fears are lower. Yet Marin (2012) still finds that individuals who know about specific job openings and who know people they think would be a good fit for those jobs often do not tell those

\footnotetext{
${ }^{1}$ These studies do not have data on whether or not a job seeker used contacts, but rather on the method through which she found a job. In general, those who are more likely to use contacts to search for jobs should also be more likely to succeed in finding a job through contacts.
} 
people about those jobs. In her sample of 37 insurance agents in a Toronto call center, she finds that they tell a job seeker they know about a job opportunity only $27 \%$ of the time. Her interviews suggest that a potential helper may be reluctant to "intrude" without a clear indication that the contact is indeed searching for a job.

\section{Direct Test}

Another way to examine the causal effect of social networks on labor-market outcomes is to conduct a direct test. The first generation of direct test studies (e.g., Granovetter 1973, Lin et al. 1981) examined the relationship between the method by which a job seeker found her job and her labor-market outcomes, such as wages or job satisfaction. However, these studies ignore the unsuccessful job searches - some of which might also have been conducted through contacts - and thus suffer from the common methodological problem of selection on the dependent variable (Montgomery 1992, Granovetter 1995, Fernandez and Weinberg 1997). Montgomery (1992) analytically demonstrated that collecting information only on the successful job searches while neglecting the unsuccessful ones produces misleading results (see also Mouw 2003).

To avoid the problem of selection on the dependent variable, the second generation of direct test studies has adopted the within-individual approach, comparing the job-search outcomes achieved by one person using different search methods (Mouw 2002, 2003, 2006; Yakubovich 2005; Obukhova 2012). ${ }^{2}$ These studies estimate the effect of using a particular method net of individual-level factors that might influence the effectiveness of the job seeker's search, including human and social capital and ascribed characteristics (such as gender and race). Because within-individual comparisons control for all sources of between-individual heterogeneity, both observed and unobserved, this approach is much better than between-individual studies at ruling out the possibility that the results are influenced by some individual-level omitted variable such as reservation wage (the lowest wage at which a job seeker will accept an offer) or personality traits. ${ }^{3}$

Although the within-individual approach is promising, studies using it have primarily relied on intertemporal data (e.g., Mouw 2002, 2003; McDonald 2011; for a recent exception, see Obukhova 2012). Specifically, these studies compare the job-search outcomes for an individual who searched for a job at two points in time, once using a formal method and once using a contact. In this way, by controlling for changes in an individual's work experience, researchers ascertain if finding a job through informal

\footnotetext{
${ }^{2}$ These studies focus on job seekers' successes in applying for particular opportunities. Inasmuch as social networks might also help a job seeker to identify good job opportunities (Granovetter 1995), the results might be a conservative estimate of the role of social networks in job search.

${ }^{3}$ Because within-individual models compare outcomes of the same individual's searches through different methods, they are not appropriate for determining which individuals might benefit the most from contacts. Each individual's characteristics, such as sex and race, are constant across her job searches.
} 
methods carries any wage premiums. Although these studies use data from the same source - the National Longitudinal Survey of Youth - they have produced contradictory results. For example, Mouw (2003) finds that job seekers do not benefit from contacts, whereas Mouw (2002) finds that the use of contacts leads to higher wages among Black workers.

The utility of intertemporal studies in answering the question of whether a job seeker benefits from contacts is limited by a potentially problematic assumption about the lack of intertemporal change in the individual's characteristics between the two points in time at which she searched for jobs. Violation of this assumption may compromise the results. The method through which a job seeker finds an earlier job may itself influence how much social and human capital she can build before she searches for her next job. For example, Castilla (2005) shows that, if hired, referred candidates initially perform better than nonreferred candidates. Thus, it is possible that those who find a job through contacts are promoted more quickly and are therefore more likely to build social and human capital before they seek their next job. If intertemporal studies do not have adequate measures of social and human capital at the two points when a job seeker searches for a job, such differences in ability to build social and human capital might bias the results.

The method through which a job seeker finds an earlier job may also influence how soon she searches for her next job. There is substantial evidence that voluntary turnover rates are lower for those who found a job through contacts than for those who did not (e.g., Neckerman and Fernandez 2003, Kmec 2007). Thus, it is likely that finding a job through a contact affects how soon a job seeker begins to search for a job again, potentially biasing the results of the intertemporal studies. Given these arguments, until we know more about how finding a job through one method or another influences an individual's ability to build human and social capital in one job and how soon an individual decides to seek her next job, we should interpret the results of intertemporal within-individual studies with considerable caution.

\section{Strategic Site: School-to-Work Transition}

To conduct a direct test that avoids the potential problems of the intertemporal approach, we used a research setting - school-to-work transition for university graduates - in which job seekers engage in contemporaneous job searches through a variety of methods. We collect information on all of the job seeker's job searches over a single continuous period before accepting her first job after college. An important advantage of this research site for collecting data on contemporaneous job searches is that, although students are likely to use a variety of methods, they search for a limited time, typically 6 to 12 months. So we can be less concerned with the accuracy of their recall of the job-search process than we would have to be with midcareer job seekers. (Pierret 2001). This is especially critical because we collect information on all the job applications that a student sends out, not only the successful ones, which are most likely to be remembered. 
Figure 2 presents a conceptual diagram of how we model an individual's job search. Four funnels (for contacts, university intermediaries, internships, and formal methods) represent different methods by which a student could learn about job opportunities. The width of the leftmost cylinder in each funnel represents the number of applications that a job seeker submits for opportunities found through that method. Each subsequent cylinder represents the number of those original applications that lead to interviews, then to offers, and finally to job acceptance. Although not all employers recruit and screen potential employees in this standard manner, most large firms use a variant of this model (Cohen and Pfeffer 1986). The nested nature of these outcomes might not accurately reflect all the complexities of the job-search process, such as issues of nonsearch (e.g., Granovetter 1973, 1995; McDonald and Elder 2006), but it provides a useful starting point for comparison across methods. Because most university graduates use contacts and other methods to search for a job, we can compare the outcomes the same individual achieves through contacts and formal methods.

For at least two reasons, the school-to-work transition offers a conservative test for evaluating how job seekers benefit from using contacts. First, we expect the benefits of social networks for job search to be particularly low among university graduates (Granovetter 1974, McDonald and Elder 2006). Graduating students, unlike midcareer job seekers, are likely to have fewer professional connections that might be useful in a job search. Thus, we might expect that they are less likely to use social networks to search for jobs. Even if they do, they might not benefit from it as much as midcareer job seekers. In addition, university graduates have two other search options - university intermediaries and internships - which, as we discuss below, provide some of the same information benefits as contacts.

The main job of university intermediaries is to help students connect to employers that are seeking to hire recent graduates of that university or have done so in the past (e.g., Rosenbaum and Kariya 1989, Rosenbaum et al. 1990, Ho 2009). Thus, it is likely that university intermediaries steer students to employers and jobs that are potentially a better fit for them with respect to their field of study or lack of work experience. It is also plausible that employers prefer to hire candidates who learned about the job opportunity through university intermediaries because employers may be more familiar with these candidates' skill sets or may benefit from having multiple alumni of the same university in their organization. As a result, we might expect that applications submitted for opportunities identified through school intermediaries have better outcomes.

Similarly, internships provide students and employers with an opportunity to learn about each other (e.g., Kalleberg 2000, Sterling 2013). During an internship, the student has a firsthand opportunity to observe characteristics of the employer that may be hard to learn about through the formal job application process, such as the company's culture and its authority relations. The employer also has an opportunity to observe the student's fit with its expectations and needs. It is likely that if the student or the employer do not find their 
fit satisfactory, the student will not try for a full-time job there. It is also plausible that employers prefer to hire candidates that have completed an internship there, reasonably assuming that in the initial post-hire period these candidates will have higher productivity and lower turnover than entirely new hires. As a result, we might expect that applications submitted for opportunities identified through internships have better outcomes.

\section{Data}

Our data were collected as part of the Future Paths project, a longitudinal study of students at four schools with engineering programs: Massachusetts Institute of Technology (MIT), the University of Massachusetts at Amherst (UMass), the Franklin W. Olin College of Engineering (Olin), and Smith College (Smith). ${ }^{4}$ In 2003, the entire freshman classes at MIT, Olin, and Smith, and 332 randomly selected UMass freshmen were invited to participate in the study. Starting in their freshman year, students received yearly online surveys.

Our sample consists of 291 students who, in the fifth wave of the survey (the fall of the year immediately following graduation), provided information about searching for a job in the last year of college or since. Of the students participating in the study, 58\% responded to the fifth wave of the survey. Compared with students who did not respond, those who did were more likely to belong to nonwhite non-Asian ethnic groups $(10.2 \%$ versus $16.1 \%, \mathrm{p}<005)$ and came from families with slightly higher adjusted parental income $(\sim 67,000$ versus $\sim \$ 81,000, p<001)$. Of those who responded, $72 \%$ reported having searched for a job during the last year of college or since. Compared with students who did not search for a job, those who did were more likely to be white $(62.0 \%$ versus $71.5 \%, \mathrm{p}<01$ ), had a lower self-reported grade point average (GPA) (4.45 versus 4.28, $\mathrm{p}$ $<0001)$, and had a slightly higher number of siblings $(0.71$ versus $0.82, \mathrm{p}<005)$.

Table 1 presents basic means and standard deviations for the descriptive characteristics of the students in our sample. As might be expected, given the sampling procedure, $41 \%$ of the students were engineering majors. The proportion is $100 \%$ at Olin, an engineeringonly school. Two of three students in the sample were female. The proportion of females was $100 \%$ at Smith, a women-only school. When asked what they were "currently doing," the majority (243) of students who reported searching for work in the last year of college or since, reported being employed, confirming that most students in our sample were searching for postgraduate jobs rather than for summer internships or part-time positions. Among the rest, 17 were in school, 11 were looking for work, 2 were taking time off, and 18 did not give a concrete response.

The questionnaire asked each student how many job applications she sent for

\footnotetext{
${ }^{4}$ For more details, see Cech et al. (2011).
} 
opportunities she learned about through each of 13 job-search methods. Although this definition of a job search might lead to underreporting of job searches through contacts (for example, it is possible that a job seeker asks many of her contacts if their employers are hiring, but only sends applications to the few that actually are hiring), it provides a useful starting point for comparison across methods. The 13 methods are advertisements, career office, college alumni network, school friends, nonschool friends, family members, internship, campus recruiter, direct contact with company, employment agency, headhunter, faculty, and other. We group school friends, nonschool friends, family members, and faculty as contacts. We also create a dummy variable for university intermediaries by grouping career office and college alumni networks and a dummy variable for internships. ${ }^{5}$ A key difference between college alumni networks and job seekers' personal contacts is that the former method is, in principle, available to any student from the same university (see Lee and Brinton 1996). We code all other methods as formal methods. ${ }^{6}$

\section{Analysis}

\section{Descriptive Results}

Table 2 reports descriptive statistics on our sample. Among 291 students, $46 \%$ searched through contacts, $56 \%$ searched through university intermediaries, $26 \%$ applied to employers with whom they had an internship, and 64\% searched through formal methods. If we only look at the likelihood of advancing to the next stage of the job-search process, contacts do not appear to benefit those who use them more than any other method. For example, $82 \%$ of those who searched through contacts received an interview; the percentages for those who searched through university intermediaries, internships, and other formal methods were $89 \%, 88 \%$, and $87 \%$, respectively. The results are substantively similar for the likelihood of receiving an offer.

However, if we consider that the number of resumes distributed through different methods varied substantially, we find some telling differences in yields across methods. On average, students who applied for job opportunities identified through contacts submitted 2.61 applications and received 1.65 interviews and 1.52 offers. Those who applied for job opportunities identified through university intermediaries distributed 6.55 applications and received 4.32 interviews and only 2.34 offers. Students who applied for

\footnotetext{
${ }^{5}$ As further robustness checks, we reran all our models with (a) alumni networks as a separate method, and (b) alumni networks included in the "contacts" category; the results remained substantively identical to those reported here.

${ }^{6}$ As further robustness checks, we reran all our models with "other" as a separate method. The results remained substantively identical to those reported here. Furthermore, among 35 students who provided valid write-in responses for other, all but seven of the methods were clearly formal.
} 
opportunities identified through a previous internship appear to have had the best labormarket outcomes; from 1.34 applications, they received 1.27 interviews and 1.26 offers. Students who applied for opportunities identified through formal methods had the lowest yield rate; from 8.53 applications, they received only 3.28 interviews and 1.97 offers.

\section{Indirect Test}

We begin by conducting an indirect test using our own data, examining whether university graduates with more social capital are more likely to search through contacts. Because a student's family is likely to be motivated to help her (Granovetter 1983, Obukhova 2012), family social capital is likely to be useful in university graduates' job searches. We create three variables to measure social resources a student can access through her family. Research has shown that those with higher socioeconomic status have access to more social resources (Lai et al. 1998, Lin 2002). Thus, we create two variables that measure the family's socioeconomic status: family income $(\mathrm{ln})$ and father's education. To measure social capital that a student might access through her siblings and their families, we also code a count variable for logged number of student's siblings: number of siblings (ln).

We also create four variables measuring a student's own social capital. Two variables measure social capital created in the university. Because a student's classmates are likely to have majors and professional aspirations similar to her own, we might expect her university friends to be useful in her job search. In the first, third, and fourth waves of the study, the survey included two questions that allow us to tap into social networks that the student had created at the university: "How many students did you interact with socially over the past two weeks?" "How many students did you interact with in completing school assignments during the past two weeks?" We use this information to construct two logged count variables for school-related social capital: number social friends (ln) and number of academic friends (ln).

The other two variables focus on whether or not a student benefited from social capital in the past. If those with more social capital are more likely to search through contacts, it is reasonable to assume that those with more social capital have already benefited from it in the past. In the first, third, and fourth waves of the study, after a question about what students did the previous summer, the survey asked, "How did you find out about the opportunity to do what you did last summer?" We use this information to code prior use of contacts, coded 1 if the student used contacts in any of these years and 0 otherwise. In the fourth wave of the study, the survey included this question: "If you are seeking employment following graduation, estimate the number of job opportunities/listings relevant for you (i.e., you plan to follow-up in some way) identified so far by each of the following methods." Students reported a number for each method listed-faculty, peers, and family. Adding these counts, we create a variable, number of opportunities through contacts (ln). 
The results presented in Table 3 show that a student's sex, race, and GPA have no statistically significant effect on the likelihood that she applied for opportunities identified through contacts, and neither do any of our measures of social capital. Then, we explored the possibility that although our measures of social capital do not have an effect on the likelihood of searching through contacts, they might have an effect on searching through particular types of contacts. In separate analyses, we examined whether any of our three family social capital variables (family income (ln), father's education, and number of siblings (ln)) have an effect on searching through family. We found that only family income ( $(\mathrm{n})$ predicted that a student searches through family. We also found that neither number social friends $(\mathrm{ln})$ nor number of academic friends $(\mathrm{ln})$ influence the likelihood that a student searches for jobs through school friends. Last, we made our models more comparable with Mouw's (2003) by predicting not whether the student searched for a job through contacts, but whether she found a job through contacts. The results are substantively similar to those reported for searching for a job through contacts. Thus, our results suggest that if we relied only on indirect test, we would conclude from our own data that graduating university students do not benefit from searching for jobs through contacts.

\section{Direct Test}

We next conduct a direct test using our data, that is, to explore, using a within-individual methodology, whether job seekers benefit from using contacts to search for jobs. To do so, the questionnaire asked how many interview opportunities and job offers the student had received via each method and which of these offers she had accepted. Using this information, we construct three dependent variables: Received an interview is coded 1 if an application led to an interview opportunity and 0 otherwise. Received an offer is coded 1 if an application led to a job offer and 0 otherwise. Accepted an offer is coded 1 if an application led to a job offer that the job seeker accepted and 0 otherwise.

To make inferences, within-individual models draw on within-individual variations on the dependent and independent variables. This means that for the received an interview model, our within-individual sample includes only applications from students who made at least two search attempts using different methods, with at least one resulting in an interview and at least one that did not (see Table 4). Among the 291 students in our study, 204 met this criterion and their 2,785 applications form the within-individual sample (column (1b)). For the received an offer model, our within-individual sample includes only applications from students who received at least two interviews though different methods, with at least one interview resulting in an offer and at least one that did not. Among the 288 students in our study who received interviews, 178 met this criterion and their 1,143 applications form the within-individual sample (column (2b)). For the accepted an offer model, our within- individual sample includes only applications from students who received at least two offers though different methods. Among the 274 students in our study who accepted offers, 170 met this criterion and their 590 
applications form the within-individual sample (column (3b)).

To test the relative effectiveness of different job-search methods, we ran individual fixedeffects linear probability models to estimate the likelihood that a job application achieves one of the three aforementioned outcomes. Some scholars (e.g., Aldrich and Nelson 1992) advise against using the linear probability model because it can theoretically yield predicted probabilities greater than 1 or less than 0 . This does not occur in our models. To address the theoretical concern about predicted values falling outside the 01 range, we also estimate a fixed-effects logit model. To address the possibility of correlations in the error terms of each individual's application outcomes, we estimate (a) fixed-effect linear probability models with clustered standard errors, and (b) fixed-effects logit models with clustered standard errors. Across these model specifications, there was no change in the direction of the results and little change in the significance of the marginal effects. For ease of interpretation, we present only the results from the linear probability models.

Table 5 presents the estimates from the linear probability models comparing the yields of applications for opportunities identified through contacts, university intermediaries, and internships relative to formal methods. University graduates benefit from searches through contacts, both overall and at each stage of the job-search process. If we only look at the ultimate outcome of the job search - whether or not the student found a job-we find that an application submitted for an opportunity identified through a contact had a 13\% higher likelihood of leading to a job than an application for an opportunity identified through formal methods (column (3a)). We also find that applications for job opportunities identified through contacts are $11 \%$ more likely to lead to an interview than applications for job opportunities identified through formal methods (column (1)). Conditional on receiving an interview, these applications are $18 \%$ more likely to result in an offer (column (2b)). Last, conditional on receiving an offer, students are $21 \%$ more likely to accept an offer for a job opportunity identified through a contact than for one identified through formal methods (column (3b)).

We also find that contacts outperform university intermediaries. Specifically, model (3a) indicates that applications submitted for job opportunities identified through school intermediaries are less likely to lead to a job than applications submitted for opportunities identified through contacts $(-0.002$ versus 0.132$)$. This difference is statistically significant (F $12813=3938, \mathrm{p}=0000)$. Most of the difference between the two methods appears in the later stages of the job-search process. Applications for opportunities identified through university intermediaries and through contacts are equally likely to lead to an interview ( 0.137 versus 0.108 ; F $12818=066, p=0415$ in model (1)). However, in later stages of the job-search process, university intermediaries perform significantly worse than contacts $(-0.021$ versus 0.184, F $11133=1393, p<0$ 001 ; and -0.174 versus $0.207, \mathrm{~F} 1438=1693, \mathrm{p}<0001$ in models (2b) and (3b), respectively).

Overall, contacts perform as well as internships. Specifically, model (3a) indicates that an 
application to an employer with whom a student had an internship is as likely to lead to a job as an application submitted for a job opportunity identified through contacts (1.61 versus 0.132 ). The difference between the two methods is not statistically significant (F 1 $2813=075, p=0385$ ). Internship does better in the earlier stages of the job-search process; an application submitted to an employer with whom a student had an internship is significantly more likely to result in an interview than an application submitted through a contact $(0.338$ versus $0.108, \mathrm{p}<0001 ; \mathrm{F} 12813=1703, \mathrm{p}=0000)$. Conditional on receiving an interview, however, the difference becomes nonsignificant in the offer stage ( 0.320 versus 0.184 ; F $11133=349, \mathrm{p}<01)$. Conditional on receiving an offer, an offer received from an employer with whom the student had an internship is significantly less likely to be accepted than an offer received for an opportunity identified through a contact $(-0.085$ versus 0.207 ; F $1438=740, \mathrm{p}<001)$.

In additional analyses, we examined whether individuals with more social capital-as measured by one of our social capital variables - benefit more from searching through contacts. Specifically, we constructed interaction terms between (a) searching through contacts and prior use of contacts and number of opportunities through contacts (ln); (b) searching through family and family income (ln), father's education, and number of siblings (ln)); and (c) searching through friends and number of social friends ( $\mathrm{ln}$ ) and number of academic friends ( $\mathrm{ln}$ ). Of 42 regressions (for each seven interaction terms we ran six regressions), in only four were the interaction terms significant, which suggests that, at $\mathrm{p}<01$, we cannot reject the possibility that the effects are generated by a random process. These results provide additional support for our contention that having social capital might not influence the outcome of a job search unless that social capital is used.

\section{Robustness Checks}

Because our sample overrepresented engineering majors, we also repeat these analyses for students who were engineering and nonengineering majors. We might expect that connections play a less important role among engineering majors for whom "fit" might matter less than hard skills. Yet additional analysis reveals only slight differences by major in students' job-search behavior. We find that the total number of applications, interviews, and offers did not differ significantly between students in different majors. We also find that students in engineering, on average, send more applications though university intermediaries than other students. They also receive more interviews through university intermediaries and fewer offers through formal methods. Within-individual analysis reveals surprisingly little difference in the effectiveness of the different methods for students in engineering and other majors. We do find that method effectiveness explains a much greater amount of variance among engineers, even though they are a smaller sample. This result likely reflects the fact that nonengineering students are applying to a more heterogeneous set of employers.

We examined two sources of potential selection bias. First, we examined differences between our sample of 291 job seekers and the entire population of students included in 
the study, including those who did not respond to our job-search questions and those who did not report searching for a job. We found that our sample differed from the entire population with respect to race, parental income, self-reported GPA, and number of siblings. We then found significant differences between our original sample and the within-individual samples for each job outcome with respect to gender, race, parental income, self-reported GPA, and major. We performed separate analyses of method effectiveness for students, splitting the sample along each one of these variables. Although the results sometimes become insignificant, as a result of small sample sizes, the direction of coefficients is consistent across the full sample and the split subsamples. Because the results for these subsamples appear to be substantively similar to those for the whole sample, it is unlikely that our results for the entire sample are simply due to underrepresentation or overrepresentation of a particular group.

\section{Discussion}

The results of this study provide important empirical support for the need to distinguish having social capital and using contacts as a search method. Consistent with existing studies (e.g., Lai et al. 1998, Mouw 2003), we find that the job seeker's amount of social capital does not predict the likelihood that she uses contacts to search for a job. However, the lack of an association between a job seeker's social capital and whether or not she uses social networks to search for a job should not be taken to imply that job seekers who use social networks to search for jobs do not benefit from doing so. Among graduating university students, we find that, although a job seeker's social capital may not affect whether or not she uses contacts to search for a job, using contacts does improve her jobsearch outcomes.

Our study provides important new evidence on the effects of searching through social networks, corroborating the evidence from single-firm studies (Fernandez and Weinberg 1997, Fernandez et al. 2000, Petersen et al. 2000, Yakubovich and Lup 2006). In contrast to previous direct test studies that used data on intertemporal job searches (e.g., Mouw 2002, 2003), our study finds that, for those who do use their social networks to search, applications for job opportunities identified through networks are more likely to result in an interview, an offer, and an acceptance than applications submitted for opportunities identified through formal methods and university intermediaries. In fact, in terms of overall yield on applications, if the job seeker actually submits an application through contacts, search through contacts is comparable only to applying to employers where a student has previously had an internship - a comparatively rare situation in which both the employer and student already have firsthand knowledge of one another.

Our results on the effectiveness of searching through university intermediaries are consistent with the literature that emphasizes the information benefits that these intermediaries provide to graduating students (e.g., Rosenbaum and Kariya 1989, Rosenbaum et al. 1990, Ho 2009). We find that job applications for opportunities 
identified through school intermediaries are more likely to result in an interview. This result is consistent with our expectation that employers prefer to hire job seekers who learned about the opportunity though university intermediaries. It is also likely that university intermediaries steer students to employers and jobs that are a better fit for them. Interestingly, we find that, unlike for social networks, for university intermediaries, neither of these effects extend past the interview stage.

Our results on the effectiveness of applying for opportunities identified through a former internship are consistent with the literature emphasizing the opportunities for direct observation that an internship offers the employer and the intern (e.g., Kalleberg 2000, Sterling 2013). We find that job applications for opportunities identified through internships have a higher success rate than applications for opportunities identified through formal methods. This suggests that employers prefer to hire job seekers who have had an internship, or that a student who did not have a good internship experience is less likely to apply for a full-time job with that employer. The fact that students are no more likely to accept job offers for opportunities identified through internships than for those identified through formal methods suggests that internships do not necessarily help a job seeker to apply for jobs for which she is better suited, but rather that the employer prefers candidates who have previously completed an internship with the company.

Note that the results on selection into searching through networks presented in Table 3 , as well as the theoretical arguments discussed above, suggest that our within-individual results are not simply attributable to self-selection of job seekers into methods. Consider that, in the absence of random assignment of students to job-search methods and inasmuch as any within-individual comparison (using intertemporal or contemporaneous data) is based on those who used social networks, estimates of how a job seeker benefits from social networks are based only on those who use contacts (Mouw 2002). If job seekers with better social capital are more likely to use social networks because they expect high returns from doing so or if job seekers with less human capital are more likely to use social networks because they expect bad returns from using other methods, this self-selection into search through contacts could upwardly bias our coefficients for search through contacts. However, although we cannot completely rule out self-selection on some unobserved variable, consistent with our theoretical arguments, we find no evidence of selection on observed social capital variables.

\section{Implications}

Our results help to solve an important puzzle in the job-search literature: Whereas singlefirm studies consistently find that job seekers benefit from using contacts in job search, the evidence from job-seeker studies is mixed (Mouw 2003). We argue that the answer to this puzzle lies in clarifying the distinction between having social capital and using contacts to search for jobs. Although we have plausible theoretical reasons to expect that job seekers benefit from using contacts as a job-search method (Simon and Warner 1992, 
Coverdill 1998, Fernandez et al. 2000), we have reasons to doubt that a job seeker with more social capital is more likely to use contacts in a job search. Using information about job searches by recent university graduates, we showed that, although a job seeker's social capital may not have an effect on whether or not she uses contacts to search for a job, using contacts does improve her job-search outcomes.

In addition, our results highlight opportunities for the within-individual approach to advance our understanding of causality in the role of social networks in labor markets. The current literature is dominated by between-individual research designs that can never completely rule out the possibility of unobserved heterogeneity (Yakubovich 2005, Mouw 2006). Several job-search studies have shown that if an important variable is unobserved and therefore omitted from the analysis, between-individual studies can lead to misleading results (Thomas 1997, Mouw 2002). In contrast, within-individual studies control for all sources of between-individual heterogeneity, both observed and unobserved, potentially offering an important improvement on between-individual approaches as a way to disentangle questions about network causality. Thus, complementing between-individual studies of single firms or individual job seekers with studies using within-individuals methodology appears to be an important direction for future research.

Last, the results of our study raise important questions for future research on agency and social networks. Social network research often assumes that individuals will take advantage of the network position in which they find themselves. However, research finds that they often do not (for a review, see Burt 2011). Consistent with these results, our study finds that, despite the fact that search through networks is beneficial, job seekers still might not use their networks. We still lack a compelling theory to explain these results. Recent studies (e.g., Smith 2005, Marin 2012, Smith et al. 2012) have made important steps in advancing our understanding of processes involved in network activation and mobilization, but more research into these processes is needed. Studies that explore these processes from the perspective of those in a position to help the job seeker, appear to be a particularly productive area for future research.

\section{Acknowledgments}

The authors thank Roberto Fernandez, Brian Rubineau, participants in MIT's Economic Sociol. Working Group, Cornell's Organizational Behavior Seminar, the People and Organizations Conference at the Wharton School of the University of Pennsylvania, the Management and Organizations Seminar at Kellogg School of Northwestern University, Delta Forum at the Department of Management at Baruch College, and the 2011 American Sociological Association session on "Current Issues in Job Search" for comments and feedback. This material is based in part on work supported by the National Science Foundation [Grants 0240817, 0241337, 0503351, 0609628] and awarded to Susan S. Silbey and Carroll Seron for "Developing Diverse Leadership for Engineering." Opinions, findings, conclusions, and recommendations expressed in this paper 
are those of the authors and do not necessarily reflect the views of the National Science

Foundation.

\section{References}

Aldrich JH, Nelson FD (1992) Linear Probability, Logit, and Probit Models (SAGE, Newbury Park, CA).

Boxman EAW, De Graaf PM, Flap HD (1991) The impact of social and human capital on the income attainment of dutch managers. Soc. Networks 13(1):51-73.

Burt RS (2011) Neighbor Networks: Competitive Advantage Local and Personal (Oxford University Press, New York).

Castilla EJ (2005) Social networks and employee performance in a call center. Amer. J. Sociol. 110(5):1243-1283.

Cech E, Rubineau B, Seron C, Silbey S (2011) Professional role confidence and gendered persistence in engineering. Amer. Sociol. Rev. 76(5):641-666.

Cohen Y, Pfeffer J (1986) Organizational hiring standards. Admin. Sci. Quart. 31(1):1-24.

Coverdill JE (1998) Personal contacts and post-hire outcomes: Theoretical and empirical notes on the significance of matching methods. Res. Soc. Stratification and Mobility 16:247-269.

de Graaf ND, Flap H (1988) With a little help from my friends: Social resources as an explanation of occupational status and income in West Germany, the Netherlands, and the United States. Soc. Forces 67(2):452-472.

Fernandez RM, Weinberg N (1997) Sifting and sorting: Personal contacts and hiring in a retail bank. Amer. Sociol. Rev. 62(6): 883-902.

Fernandez RM, Castilla EJ, Moore P (2000) Social capital at work: Networks and employment at a phone center. Amer. J. Sociol. 105(5):1288-1356.

Granovetter M (1973) The strength of weak ties. Amer. J. Sociol. 78(6):1360-1380.

Granovetter M (1983) The strength of weak ties: A network theory revisited. Sociol. Theory 1:201-233.

Granovetter M (1995) Getting a Job: A Study of Contacts and Careers, 2nd ed. (University of Chicago Press, Chicago). [First edition originally published 1974.]

Ho K (2009) Liquidated: An Ethnography of Wall Street (Duke University Press, Durham, NC).

Holzer HJ (1987) Informal job search and black youth unemployment. Amer. Econom. Rev. 77(3):446452.

Kalleberg AL (2000) Nonstandard employment relations: Part-time, temporary, and contract work. Annual Rev. Sociol. 26:341-365.

Kmec JA (2007) Ties that bind? Race and networks in job turnover. Soc. Problems 54(4):483-503. 
Lai G, Lin N, Leung S-Y (1998) Network resources, contact resources, and status attainment. Soc. Networks 20(2):159-178.

Lee S, Brinton MC (1996) Elite education and social capital: The case of South Korea. Sociol. Ed. 69(3):177-192.

Lin N (2002) Social Capital: A Theory of Social Structure and Action, 1st ed. (Cambridge University Press, New York).

Lin N, Vaughn JC, and Ensel WM (1981) Social resources and occupational status attainment. Soc. Forces 59(4):1163-1181.

Marin A (2012) Don't mention it: Why people don't share job information, when they do, and why it matters. Soc. Networks 34(2):181-192.

Marsden P, Gorman EH (2001) Social networks, job changes, and recruitment. Berg I, Kalleberg AL, eds. Sourcebook of Labor Markets: Evolving Structures and Processes (Kluwer Academic/ Plenum, New York), 467-502.

McDonald S (2011) What you know or who you know? Occupation-specific work experience and job matching through social networks. Soc. Sci. Res. 40(6):1664-1675.

McDonald S, Elder GH (2006) When does social capital matter? Non-searching for jobs across the life course. Soc. Forces 85(1):521-549.

Montgomery JD (1992) Job search and network composition: Implications of the strength-of-weak-ties hypothesis. Amer. Sociol. Rev. 57(5):586-596.

Mouw T (2002) Racial differences in the effects of job contacts: Conflicting evidence from crosssectional and longitudinal data. Soc. Sci. Res. 31(4):511-538.

Mouw T (2003) Social capital and finding a job: Do contacts matter? Amer. Sociol. Rev. 68(6):868-898.

Mouw T (2006) Estimating the causal effect of social capital: A review of recent research. Annual Rev. Sociol. 32(1):79-102.

Neckerman K, Fernandez RM (2003) Keeping a job: Network hiring and turnover in a retail bank. Res. Sociol. Organ. 20:299-318.

Obukhova E (2012) Motivation vs. relevance: Using strong ties to find a job in China. Soc. Sci. Res. 41(3):470-480.

Petersen T, Saporta I, Seidel M-DL (2000) Offering a job: Meritocracy and social networks. Amer. J. Sociol. 106(3):763-816.

Pierret CR (2001) Event history data and survey recall: An analysis of the national longitudinal survey of youth 1979 recall experiment. J. Human Resources 36(3):439-466.

Rosenbaum JE, Kariya T (1989) From high school to work: Market and institutional mechanisms in Japan. Amer. J. Sociol. 94(6): 1334-1365. 
Rosenbaum JE, Kariya T, Settersten R, Maier T (1990) Market and network theories of the transition from high school to work: their application to industrialized societies. Annual Rev. Sociol. 16:263-299.

Simon CJ, Warner JT (1992) Matchmaker, matchmaker: The effect of old boy networks on job match quality, earnings, and tenure. J. Labor Econom. 10(3):306-329.

Smith EB, Menon T, Thompson L (2012) Status differences in the cognitive activation of social networks. Organ. Sci. 23(1): 67-82.

Smith SS (2005) Don't put my name on it: Social capital activation and job-finding assistance among the black urban poor. Amer. J. Sociol. 111(1):1-57.

Sterling A (2013) Friendships and search behavior in labor markets. Working paper, Washington University in St. Louis, St. Louis.

Thomas JM (1997) Public employment agencies and unemployment spells: Reconciling the experimental and nonexperimental evidence. Indust. Labor Relations Rev. 50(4):667-683.

Völker B, Flap H (2001) Weak ties as a liability. Rationality Soc. 13(4):397-428.

Yakubovich V (2005) Weak ties, information, and influence: How workers find jobs in a local Russian labor market. Amer. Sociol. Rev. 70(3):408-421.

Yakubovich V, Lup D (2006) Stages of the recruitment process and the referrer's performance effect. Organ. Sci. 17(6):710-723. 
Figure 1. Schematic Summary of the Existing Research on Social Networks and Job Search

\section{Indirect test studies}

Between-individual test for the association between a job-seeker's social capital and using social networks in job search.

Examples: Lai, Lin, and Leung 1998; Mouw 2003.

Main result: No association.

Potential problems: Assumptions about job-seeker's inclination and ability to ask for and/or receive help from contacts.

\section{Direct test studies (1st generation)}

Between-individual test for the association between finding a job through networks and labor-market outcomes.

Examples: Granovetter 1973; Lin, Vaughn, and Ensel 1989

Main result: Mixed.

Potential problem: Ignoring unsuccessful searches.

Direct test studies (2nd generation)

Within-individual test for the association between using social networks and labor-market outcomes.

Examples: Mouw 2002, 2003.

Main result: Mixed.

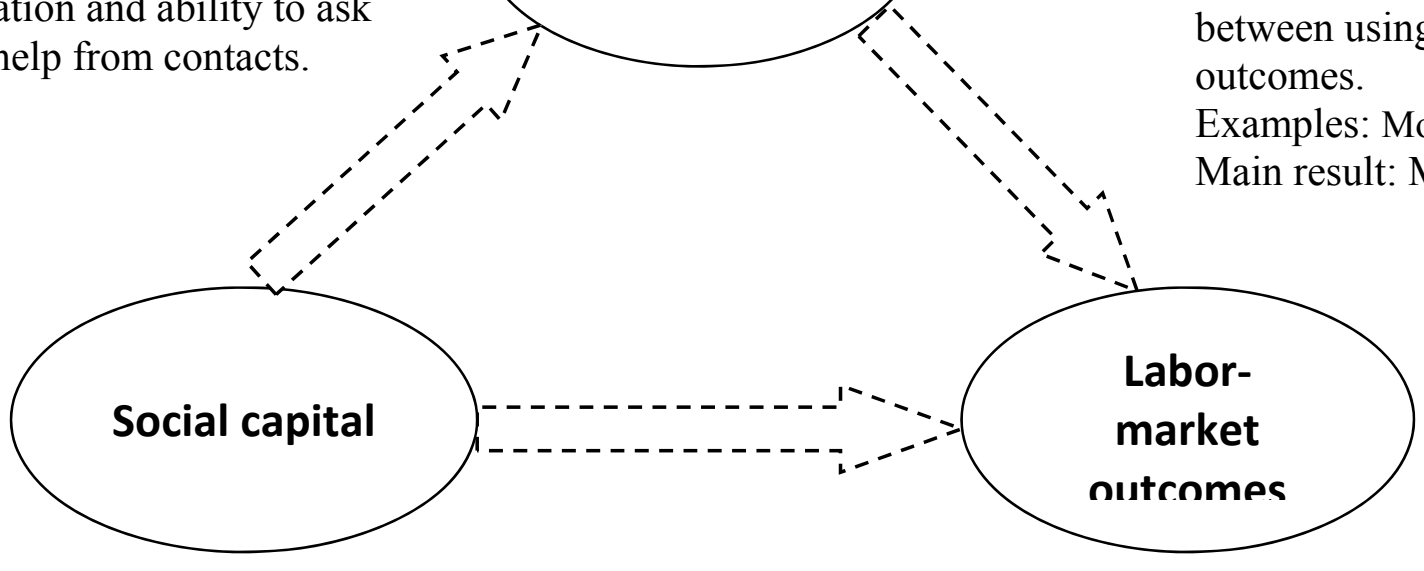

Social capital studies

Between-individual test for the association

between a job-seeker's social capital and her labor-market outcomes.

Examples: de Graaf and Flap 1988;

Boxman,Völker and Flap 2001.

Main result: Positive association.

Potential problem: Homophily in friendship networks. 
Figure 2: Illustrative Funnel Diagram of a Single Job Seeker's Applications and Progress Through Stages of the Hiring Process

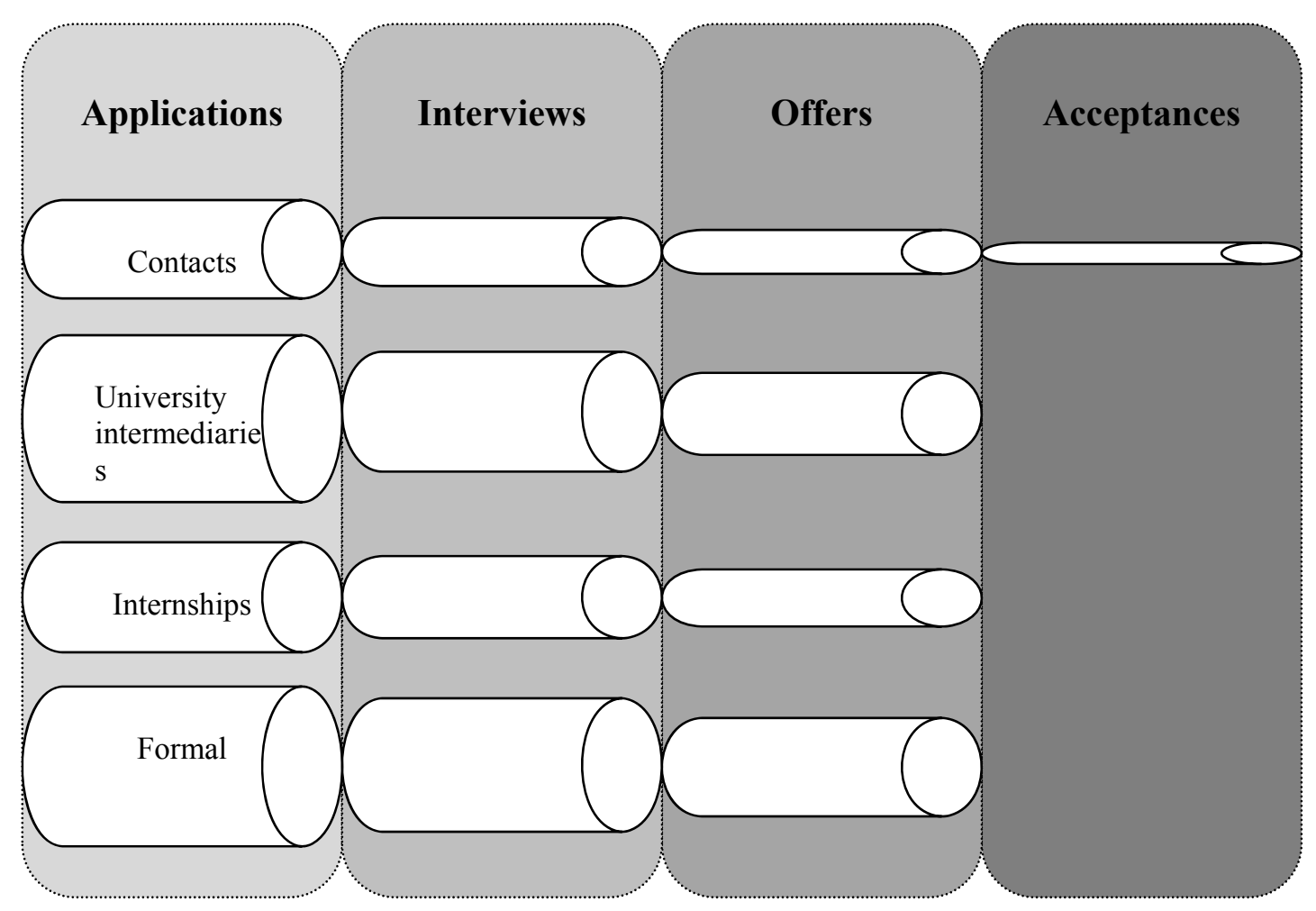


Table 1. Descriptive Statistics of Students Who Searched for a Job

\begin{tabular}{|c|c|c|c|c|c|}
\hline & $\begin{array}{l}\text { MIT } \\
(1)\end{array}$ & $\begin{array}{l}\text { Olin } \\
(2)\end{array}$ & $\begin{array}{l}\text { Smith } \\
(3)\end{array}$ & $\begin{array}{c}\text { UMass } \\
(4)\end{array}$ & $\begin{array}{c}\text { All schools } \\
(5)\end{array}$ \\
\hline \multicolumn{6}{|l|}{ Major (percentage) $^{a}$} \\
\hline Humanities & 2 & 0 & 41 & 4 & 14 \\
\hline Social sciences & 5 & 0 & 27 & 13 & 13 \\
\hline Engineering & 58 & 100 & 7 & 31 & 41 \\
\hline Math/physical sciences & 32 & 0 & 21 & 27 & 25 \\
\hline Business & 15 & 0 & 10 & 27 & 14 \\
\hline Number of students & 130 & 23 & 90 & 48 & 291 \\
\hline \multicolumn{6}{|l|}{ Gender (percentage) ${ }^{b}$} \\
\hline Female & 57 & 40 & 100 & 37 & 67 \\
\hline \multicolumn{6}{|l|}{ Race (percentage) $)^{b, c}$} \\
\hline White & 52 & 85 & 84 & 93 & 72 \\
\hline Asian & 38 & 25 & 8 & 2 & 22 \\
\hline Other & 12 & 0 & 9 & 5 & 9 \\
\hline Number of students & 121 & 20 & 90 & 43 & 274 \\
\hline \multicolumn{6}{|c|}{$\begin{array}{l}{ }^{a} \text { Except at Olin, the percentages of majors for a school add up to more than } 100 \% \text { because } 21 \text { students had double } \\
\text { majors and one student had a triple major. } \\
\text { be use data from the first wave of the study to code students' gender and race and data from the fifth wave to } \\
\text { code students' majors. Not all students responded to the gender/race questions in the first wave, which explains } \\
\text { the slight discrepancy in the totals for these demographic statistics. } \\
\text { c Biracial students are counted in both categories, so percentages for race add up to more than } 100 \% \text { in some } \\
\text { columns. }\end{array}$} \\
\hline
\end{tabular}


Table 2. Distribution of Students and Their Labor-Market Outcomes by Job-Search Method

\begin{tabular}{|c|c|c|c|c|c|}
\hline Job-search method & Contacts & $\begin{array}{c}\text { University } \\
\text { intermediaries } \\
\end{array}$ & Internships & $\begin{array}{l}\text { Other } \\
\text { formal }\end{array}$ & $\begin{array}{c}\text { Any } \\
\text { method }\end{array}$ \\
\hline & $(1)$ & $(2)$ & (3) & $(4)$ & $(5)$ \\
\hline \multicolumn{6}{|l|}{ Students who applied through method } \\
\hline Number of students & 135 & 162 & 76 & 187 & 291 \\
\hline $\begin{array}{l}\text { As percentage of all students who } \\
\text { searched }\end{array}$ & 46 & 56 & 26 & 64 & 100 \\
\hline $\begin{array}{l}\text { Mean number of resumes } \\
\text { submitted }\end{array}$ & 2.61 & 6.55 & 1.34 & 8.53 & 10.69 \\
\hline \multicolumn{6}{|c|}{ Students who received interviews through method } \\
\hline Number of students & 111 & 144 & 67 & 163 & 288 \\
\hline $\begin{array}{l}\text { As percentage of all students who } \\
\text { applied through this method }\end{array}$ & 82 & 89 & 88 & 87 & 99 \\
\hline $\begin{array}{l}\text { Mean number of interviews } \\
\text { received }\end{array}$ & 1.65 & 4.32 & 1.27 & 3.28 & 4.94 \\
\hline \multicolumn{6}{|c|}{ Students who received offers through method } \\
\hline Number of students & 91 & 111 & 57 & 124 & 274 \\
\hline $\begin{array}{l}\text { As percentage of all students who } \\
\text { received interviews through this } \\
\text { method }\end{array}$ & 76 & 82 & 77 & 85 & 95 \\
\hline Mean number of offers received & 1.52 & 2.34 & 1.26 & 1.97 & 2.61 \\
\hline \multicolumn{6}{|c|}{ Students who found a job through method } \\
\hline Number of students & 71 & 73 & 26 & 90 & 260 \\
\hline $\begin{array}{l}\text { As percentage of all students who } \\
\text { received offers through this } \\
\text { method }\end{array}$ & 78 & 66 & 46 & 73 & 95 \\
\hline
\end{tabular}


Table 3: Marginal Effects of Probit Regressions on Searching for a Job Through Contacts

\begin{tabular}{|c|c|c|c|c|c|c|c|c|c|}
\hline & \multirow[t]{2}{*}{$\begin{array}{c}\text { Means } \\
\text { (st. dev.) }\end{array}$} & \multicolumn{8}{|c|}{ Searching through contacts } \\
\hline & & (1) & (2) & (3) & (4) & (5) & (6) & (7) & (8) \\
\hline \multicolumn{10}{|l|}{ Controls } \\
\hline Female $^{a}$ & $\begin{array}{c}0.702 \\
(0.458)\end{array}$ & $\begin{array}{l}-0.110 \\
(-1.32)\end{array}$ & $\begin{array}{l}-0.123 \\
(-1.46)\end{array}$ & $\begin{array}{l}-0.109 \\
(-1.32)\end{array}$ & $\begin{array}{l}-0.110 \\
(-1.32)\end{array}$ & $\begin{array}{l}-0.113 \\
(-1.36)\end{array}$ & $\begin{array}{l}-0.129 \\
(-1.48)\end{array}$ & $\begin{array}{l}-0.129 \\
(-1.48)\end{array}$ & $\begin{array}{l}-0.131 \\
(-1.49)\end{array}$ \\
\hline Nonwhite $^{a}$ & $\begin{array}{c}0.314 \\
(0.465)\end{array}$ & $\begin{array}{c}-0.0911 \\
(-1.19)\end{array}$ & $\begin{array}{l}-0.085 \\
(-1.06)\end{array}$ & $\begin{array}{l}-0.088 \\
(-1.12)\end{array}$ & $\begin{array}{l}-0.091 \\
(-1.18)\end{array}$ & $\begin{array}{l}-0.081 \\
(-1.04)\end{array}$ & $\begin{array}{l}-0.134 \\
(-1.68)\end{array}$ & $\begin{array}{l}-0.136 \\
(-1.68)\end{array}$ & $\begin{array}{l}-0.131 \\
(-1.63)\end{array}$ \\
\hline$G P A^{b}$ & $\begin{array}{c}4.261 \\
(0.399)\end{array}$ & $\begin{array}{l}-1.635 \\
(-1.20)\end{array}$ & $\begin{array}{l}-1.542 \\
(-1.16)\end{array}$ & $\begin{array}{l}-1.637 \\
(-1.21)\end{array}$ & $\begin{array}{l}-1.635 \\
(-1.20)\end{array}$ & $\begin{array}{l}-1.617 \\
(-1.18)\end{array}$ & $\begin{array}{l}-1.313 \\
(-0.97)\end{array}$ & $\begin{array}{l}-1.336 \\
(-0.96)\end{array}$ & $\begin{array}{l}-1.455 \\
(-1.01)\end{array}$ \\
\hline$G P A^{2}$ & $\begin{array}{l}18.32 \\
(3.27)\end{array}$ & $\begin{array}{c}0.194 \\
(1.18)\end{array}$ & $\begin{array}{c}0.183 \\
(1.14)\end{array}$ & $\begin{array}{c}0.194 \\
(1.19)\end{array}$ & $\begin{array}{c}0.194 \\
(1.19)\end{array}$ & $\begin{array}{l}0.191 \\
(1.16)\end{array}$ & $\begin{array}{l}0.153 \\
(0.93)\end{array}$ & $\begin{array}{l}0.155 \\
(0.92)\end{array}$ & $\begin{array}{l}0.170 \\
(0.98)\end{array}$ \\
\hline \multicolumn{10}{|l|}{ Social capital } \\
\hline Logged family income & $\begin{array}{c}11.296 \\
(0.765)\end{array}$ & - & $\begin{array}{l}0.009 \\
(0.20)\end{array}$ & - & - & - & - & - & - \\
\hline Father's education & $\begin{array}{c}8.406 \\
(2.112)\end{array}$ & - & - & $\begin{array}{l}0.004 \\
(0.23)\end{array}$ & - & - & - & - & - \\
\hline Logged number of siblings & $\begin{array}{c}0.872 \\
(0.401)\end{array}$ & - & - & - & $\begin{array}{l}0.002 \\
(0.03)\end{array}$ & - & - & - & - \\
\hline Previous use of contacts & $\begin{array}{c}0.623 \\
(0.486)\end{array}$ & - & - & - & - & $\begin{array}{l}0.058 \\
(0.84)\end{array}$ & - & - & - \\
\hline $\begin{array}{l}\text { Logged number of job } \\
\text { opportunities from } \\
\text { contacts }\end{array}$ & $\begin{array}{c}2.483 \\
(0.254)\end{array}$ & - & - & - & - & - & $\begin{array}{l}0.096 \\
(0.70)\end{array}$ & - & - \\
\hline Logged social ties & $\begin{array}{c}3.343 \\
(0.542)\end{array}$ & - & - & - & - & - & - & $\begin{array}{l}-0.037 \\
(-0.56)\end{array}$ & - \\
\hline Logged academic ties & $\begin{array}{c}2.512 \\
(0.230)\end{array}$ & - & - & - & - & - & - & - & $\begin{array}{l}-0.214 \\
(-1.38)\end{array}$ \\
\hline Observations & 239 & 239 & 228 & 239 & 239 & 239 & 219 & 219 & 219 \\
\hline Degrees of freedom & - & 6 & 7 & 7 & 7 & 7 & 7 & 7 & 7 \\
\hline $\operatorname{LR} \chi^{2}$ & - & 9.185 & 9.102 & 9.241 & 9.186 & 9.892 & 13.92 & 13.74 & 15.36 \\
\hline Log likelihood & - & -160.7 & -153.2 & -160.7 & -160.7 & -160 & -144.6 & -144.7 & -143.8 \\
\hline
\end{tabular}

Note. All models include university fixed effects; $z$-values in parentheses unless noted; all marginal effects are calculated for white males with average

values of adjusted GPA and adjusted $\mathrm{GPA}^{2}$. * $p<0.05 ; * * p<0.01 ; * * * p<0.001$

${ }^{\mathrm{a}} d y / d x$ is for discrete change of dummy variable from 0 to 1 .

${ }^{\mathrm{b}}$ Based on self-reports. 
Table 4. Distribution of Job-Search Attempts, Interviews, and Offers by Search Method

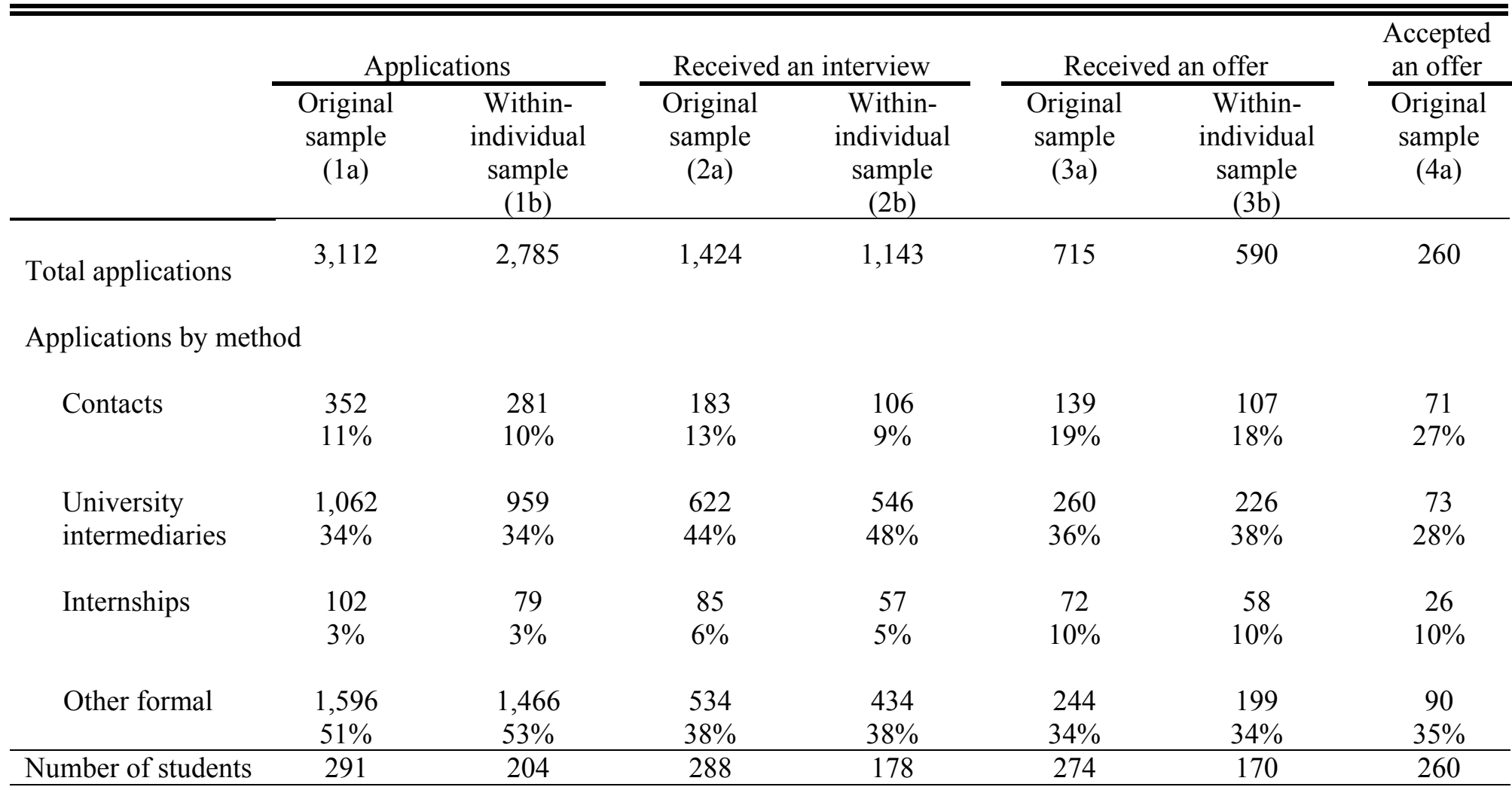

Note. Percentages are of number of applications from that method relative to total applications at that stage; that is, in column (2a), job applications through university intermediaries make up 44\% (622 out of 1,424) of the total applications that resulted in an interview. 
Table 5. Linear Probability Models of the Likelihood of Progressing to the Next Stage of the Hiring Process

\begin{tabular}{|c|c|c|c|c|c|}
\hline & \multirow{2}{*}{$\begin{array}{c}\begin{array}{c}\text { Received an } \\
\text { interview }\end{array} \\
\text { Applying } \\
\text { (1) }\end{array}$} & \multicolumn{2}{|c|}{ Received an offer } & \multicolumn{2}{|c|}{ Accepted an offer } \\
\hline & & $\begin{array}{c}\text { Applying } \\
\text { (2a) }\end{array}$ & $\begin{array}{c}\text { Interview } \\
(2 \mathrm{~b})\end{array}$ & $\begin{array}{c}\text { Applying } \\
\text { (3a) }\end{array}$ & $\begin{array}{l}\text { Offer } \\
(3 b)\end{array}$ \\
\hline \multicolumn{6}{|l|}{ Search method } \\
\hline Contacts & $\begin{array}{c}0.108 * * * \\
(3.47)\end{array}$ & $\begin{array}{c}0.132 * * * \\
(5.08)\end{array}$ & $\begin{array}{c}0.184 * * \\
(3.27)\end{array}$ & $\begin{array}{c}0.132 * * * \\
(6.93)\end{array}$ & $\begin{array}{c}0.207 * \\
(2.36)\end{array}$ \\
\hline $\begin{array}{l}\text { University } \\
\text { intermediaries }\end{array}$ & $\begin{array}{c}0.137 * * * \\
(5.00)\end{array}$ & $\begin{array}{c}0.0460 * \\
(2.01)\end{array}$ & $\begin{array}{c}-0.0214 \\
(-0.38)\end{array}$ & $\begin{array}{l}-0.002 \\
(-0.15)\end{array}$ & $\begin{array}{l}-0.174 \\
(-1.86)\end{array}$ \\
\hline Internships & $\begin{array}{c}0.338 * * * \\
(6.66)\end{array}$ & $\begin{array}{c}0.428 * * * \\
(10.11)\end{array}$ & $\begin{array}{c}0.320 * * * \\
(5.27)\end{array}$ & $\begin{array}{c}0.161 * * * \\
(5.22)\end{array}$ & $\begin{array}{c}-0.0846 \\
(-0.78)\end{array}$ \\
\hline Constant & $\begin{array}{c}0.387 * * * \\
(28.04)\end{array}$ & $\begin{array}{c}0.469 * * * \\
(16.09)\end{array}$ & $\begin{array}{c}0.469 * * * \\
(15.08)\end{array}$ & $\begin{array}{c}0.064 * * * \\
(7.56)\end{array}$ & $\begin{array}{c}0.392 * * * \\
(7.38)\end{array}$ \\
\hline Observations & 3,112 & 3,112 & 1,424 & 3,112 & 715 \\
\hline $\mathrm{R}^{2}$ & 0.0731 & 0.0742 & 0.0759 & 0.0390 & 0.0280 \\
\hline Number of students & 291 & 291 & 288 & 291 & 274 \\
\hline
\end{tabular}

Notes. Coefficients are the difference in the probability of an outcome for each method; dropped search method is formal search methods. The vertical bars represent "conditional on."

$* p<0.05 ; * * p<0.01 ; * * * p<0.001$ 